\title{
Tecnologias no aprendizado e no ensino da leitura e da escrita em perspectiva psicolinguística e interfaces
}

\section{Technologies in learning and teaching of reading and writing in a psycholinguistic perspective and interfaces}

Vera Wannmacher Pereira ${ }^{1}$, Fernanda Leopoldina Viana ${ }^{2}$, Tamiris Machado Gonçalves ${ }^{3}$

1 Bolsista em Produtividade DT do CNPq, possui mestrado e doutorado em Letras (area de concentração em Linguística Aplicada) pela Pontificia Universidade Católica do Rio Grande do Sul - PUCRS. PUCRS. Coordena o Centro orientedora na para 0 Desenvolvimento da Linguagem para O Desenvolvimento da Linguagem estão situados na Psicolinguística. E-mail: vpereira@pucrs.b

2 Doutora em Psicologia pela Universidade do Minho (Portugal). E professora associada no Instituto de Educação da Universidade do Minho. E autora de vários testes de avaliação psicológica (publicados entre 2010 e 2014) - um capitulo da obra O ensino da leitura: a avaliação (Viana, 2009), editado pelo Ministério da Educação.

3-mail: fviana@ie.uminho.pt em Linguística, pela Pontifícia Universidade Católica do Rio Grande do Sul - PUCRS. Pós-Graduada no curso Ensino de gramática da Língua Portuguesa pela Faculdade PortoAlegrense - FAPA. Licenciada em Letras Português/Espanhol pela Universidade Federal do Rio Grande - FURG. Atualmente, é aluna de doutorado no curso de Pósgraduaçăo em Letras da PUCRS, área de E-mail: mtamiris@gmail.com
A s avaliações oficiais sobre o desempenho em leitura e escrita de estudantes brasileiros indicam dificuldades na compreensão e na produção de textos, que interferem no aprendizado de conhecimentos desenvolvidos nas diversas disciplinas do currículo escolar. Os índices de provas como as aplicadas pelo Programa Internacional de avaliação de estudantes (PISA), pelo Sistema de avaliação da Educação Básica (SAEB) e pelo Sistema de Avaliação de Rendimento Escolar do Rio Grande do Sul (SAERS) vão ao encontro dessas afirmações. Os resultados do Exame Nacional do Ensino Médio também têm algo a informar sobre os problemas na compreensão e na produção de textos dos brasileiros.

Essa situação é reconhecida pela família, pela escola, pelos empregadores e pelo próprio aluno, uma vez que limita a consciência do jovem sobre o que ocorre no mundo, põe barreiras na sua construção como cidadão, dificulta seu acesso aos níveis superiores de escolaridade, reduz seu preparo para o mundo do trabalho e gera preocupações sobre os efeitos no desenvolvimento do país. Desse modo, todos que constituem a sociedade compartilham as responsabilidades por esse quadro. À academia cabe contribuir com os conhecimentos científico-pedagógicos próprios desse lugar, publicando-os e socializando-os a fim de fazer circular propostas de intervenção para essa situação.

Com o objetivo do entendimento do que está ocorrendo, pesquisadores da área da linguagem vêm se dedicando a examinar cientificamente o problema e a buscar caminhos produtivos que contribuam para as desejadas soluções. Em diferentes perspectivas, os estudos linguísticos, ancorados em paradigmas diversos, com metalinguagem e modo próprios de analisar os objetos, buscam compreender a situação e apresentar propostas que possam, de algum modo, iluminar essa questão das dificuldades de leitura e escrita. 
A Psicolinguística, no que lhe diz respeito, em interface com outros campos da Linguística (Linguística do Texto, Teoria da Enunciação, Análise do Discurso, Pragmática), com a Literatura, com as Neurociências, com a Fonoaudiologia, com a Psicologia Cognitiva, com a Computação e com a Pedagogia vem sendo uma base relevante para a realização de tais análises e para o encontro de rotas pedagógicas, especialmente ao eleger as tecnologias virtuais e não virtuais como possibilidades significativas para o aprendizado e o ensino da leitura e da escrita.

Neste número da revista Letrônica - v. 9, n. 2, 2016 -, encontram-se textos de estudiosos interessados em contribuir para a análise e para a solução da situação aqui apresentada. Esses artigos têm como tema "tecnologias no aprendizado e no ensino da leitura e da escrita em perspectiva psicolinguística e interfaces", isto é, são produções que contemplam discussões acerca do ensino e do aprendizado da leitura e da escrita, resultantes de pesquisas bibliográficas ou empíricas, com o aporte de alguma tecnologia, em diferentes perspectivas metodológicas.

Constitui-se este dossiê de doze textos, desenvolvidos nessa temática e nessa perspectiva. Seus autores, integrados a universidades nacionais e estrangeiras, disponibilizam suas iniciativas e seus achados, evidenciando gosto pelo recorte teórico-metodológico proposto, ao mesmo tempo em que, mostram seu comprometimento com a situação de aprendizado do momento.

Ao percorrer o sumário, é possível perceber que os textos, sempre tratando do aprendizado e do ensino da leitura com uso de tecnologias, apresentam também especificidades que às vezes se repetem, às vezes se entrelaçam. Disso decorre uma certa diversidade de tópicos, como dificuldades de aprendizagem, ferramentas de pesquisa e aprendizado, textos com imagens ou textos que discorrem acerca do ensino da leitura por meio de recursos tecnológicos.

Na abertura do dossiê de Linguística, encontra-se o artigo intitulado Intervenção precoce nas dificuldades de aprendizagem da leitura com recurso ao software Graphogame (Early intervention in reading difficulties using the Graphogame software), de Ana Sucena (PPorto), Ana Filipa Silva (PPorto) e Fernanda Leopoldina Viana (UMinho), que expõe a avaliação do impacto de um software de apoio às dificuldades de aprendizagem na leitura - o Graphogame - ao nível das relações letrasom, consciência fonêmica, leitura de palavras e leitura de pseudopalavras.

No âmbito de dificuldades de aprendizagem, Inmaculada Escudero (UNED), Paloma Martínez (UNED) e José Antonio León (UAM), em Los movimientos oculares como herramienta metodológica para el estudio de las dificultades de lectura en niños con TDAH (Eye tracking as a methodology for the study of reading difficulties in ADHD children) relatam estudo com o objetivo de mostrar a utilidade que a metodologia de movimentos oculares tem para o estudo de Transtornos por Déficit de Atenção com Hiperatividade, bem como abordam a questão da análise das dificuldades de leitura de crianças com TDAH. 
Nessa mesma direção, em Avaliação de softwares educacionais indicados ao aprendizado inicial da leitura e da escrita (Educational software evaluation indicated the initial learning of reading and writing), Catiane Silva Santos (UESB) e Ronei Guaresi (UESB) apresentam estudo experimental que se enquadra no contexto do ensino e do aprendizado inicial da leitura e da escrita ao avaliar softwares com indicação para casos de aprendizado abaixo do esperado.

Leandro Lemes do Prado (PUCRS), em Considerações sobre a elaboração de um instrumento de pesquisa virtual para investigar a consciência textual no ensino do gênero textual conto (Considerations on the establishment of textual consciousness in teaching the genre short story), propõe a análise de um instrumento de pesquisa que investiga a consciência textual do gênero conto por parte de professores da educação básica. Esse instrumento visa a observar a consciência textual dos próprios professores, considerando sua percepção sobre os elementos linguísticos do texto e suas relações com o contexto.

Em Parafrasear: Por quê? Para quê? (Paraphrasing: why and what for?), Onici Claro Flôres (UNISC) examina a paráfrase como um processo linguístico-cognitivo, fundamentando-se em estudos neurocientíficos. Seu artigo tem como objetivo destacar a importância da repetição e da paráfrase para a construção do conhecimento, através de uma retrospectiva de estudos já realizados sobre o tema. Sugere também sua importância para a pesquisa e para o ensino.

O texto Leitura de charges: questões metodológicas (Reading cartoons: methodological issues), de Tamiris Machado Gonçalves (PUCRS), tem como tema a compreensão da charge sob a perspectiva do Círculo de Bakhtin, sobretudo a partir das noções de signo ideológico, gêneros discursivos e vozes sociais. Busca também o entendimento do conceito de compreensão leitora, construindo com a Psicolinguística uma interface para entender os processos cognitivos usados na leitura da charge. Ademais, o artigo apresenta informações acerca do Google Formulários, tecnologia on-line que, entre suas possibilidades de uso, permite gerar fórmulas para criar ou coletar os mais diversos tipos de dados por meio de diferentes pesquisas; no artigo é apresentado um exemplo de atividades envolvendo charges.

Em Oficina de leitura e escrita inspirada em literatura, cinema e fantástico (Reading and writing workshop inspired on literature, cinema and fantastic), Alessandra da Rosa Trindade Camilo (UniRitter), Simone Becker (UniRitter) e Valdirene Alves Fontanella (UniRitter) apresentam estudo edificado a partir do desenvolvimento de uma oficina de leitura e escrita com vistas à promoção da interação e da reflexão sobre a leitura de sentidos de palavras em diferentes contextos e suportes, ao estímulo da produção escrita espontânea e criativa, à apresentação das múltiplas visões dos alunos e a colocação deles como sujeitos no processo.

Em $O$ uso do dicionário como estratégia metacognitiva de aquisição lexical na leitura em mídia virtual e imprensa (Dictionary use as a metacognitive strategy for lexical acquisition in the reading process: virtual and printed media), Claudia Finger-Kratochvil (UFFS) e Margarete G. M. de Carvalho (IFSC) apresentam resultados de uma pesquisa psicolinguística, 
pré-experimental, que verificou o desenvolvimento da estratégia do uso do dicionário para a aquisição do conhecimento lexical a partir de material impresso e virtual na construção da competência leitora.

O texto Intertextualidade e compreensão leitora: ensino da leitura com apoio da tecnologia (Intertextuality and reading comprehension: teaching reading with the support of technology), de Danielle Baretta (PUCRS) e Jésura Lopes Chaves (CM de Porto Alegre), é desenvolvido com o objetivo de demonstrar como a tecnologia pode apoiar o ensino, apresentando, para isso, um objeto de aprendizagem voltado para o desenvolvimento da habilidade da compreensão leitora a partir da intertextualidade.

Em Recursos educacionais multimidiáticos para o estímulo à leitura na educação infantil (Educational resources multimediatics for reading in early chilhood education), Elenice Larroza Andersen (UFSC) analisa recursos multimidiáticos educacionais para a leitura na educação infantil, disponibilizados em uma plataforma governamental, defendendo que o seu uso nessa fase requer atenção especial, principalmente quanto à sua adequação às necessidades cognitivas e linguísticas do público-alvo.

Gabriela Fontana Abs da Cruz (PUCRS), Gabrielle Perotto de Souza da Rosa (PUCRS), Patricia de Andrade Neves (PUCRS) e Patrícia Martins Valente (PUCRS), em Ferramentas tecnológicas para o desenvolvimento da atenção e da percepção da progressão temática no texto (Technological tools for developing attention and thematic progression perception in text), apresentam um estudo com o objetivo de avaliar a funcionalidade de três ferramentas tecnológicas - Hot Potatoes, Ardora e JClic -, utilizadas em atividades virtuais construídas para trabalhar o desenvolvimento da atenção durante a leitura e da percepção da progressão temática do texto lido.

$\mathrm{O}$ artigo que encerra o dossiê é intitulado Um elo entre letramento crítico digital e o ensino de inglês para a formação de leitores (A link between critical literacy and English teaching for the development of the readers), de Nelza Mara Pallu (UEOP). Esse texto apresenta uma experiência feita com o objetivo de enriquecer a formação de professores, de forma a possibilitar que eles interagissem de maneira mais contundente na formação de leitores, propiciando, assim, condições significativas à aprendizagem de línguas estrangeiras.

A sequência de artigos exposta nesta apresentação evidencia o racional subjacente à organização do dossiê de Linguística. Teoricamente, tem apoio na Psicolinguística em recorte de interfaces internas com campos da Linguística e de interfaces externas com outras áreas que se associam produtivamente a ela. Esse recorte integrador favorece o entendimento de sua importância, estimulando estudos que busquem essas conexões e ampliem e aprofundem a própria Psicolinguística. Metodologicamente, a Tecnologia tem um espaço especial, pois favorece as alianças teóricas e o desenvolvimento dos tópicos selecionados pelos autores. Tematicamente, o aprendizado e o ensino da leitura consistem no objeto dos estudos 
expostos, assumindo uma dimensão científico-pedagógica de valor social, uma vez que tem correspondência com o quadro educacional apresentado no início desta apresentação.

Assim configurado, o dossiê de Linguística deste número da Letrônica, resultante do trabalho de professores pesquisadores e de estudantes de pós-graduação, gerado pela parceria de organização entre a Pontifícia Universidade Católica do Rio Grande do Sul - PUCRS (Profa. Dra. Vera Wannmacher Pereira e a Profa. Ma. Tamiris Machado Gonçalves) e a Universidade do Minho (Profa. Dra. Fernanda Leopoldina Viana) e pelo compromisso com as escolas e com a Educação Básica, cumpre seu propósito de disponibilização à sociedade de conhecimentos acadêmicos construídos, na expectativa de contribuição para o aprendizado e o ensino da leitura com uso de tecnologias.

Boa leitura! 